\title{
MARÍLIA LIBRANDI
}

ROCHA é professora de

Teoria da Literatura na

Universidade Estadual do

Sudoeste da Bahia (UESB)

e editora de Fólio: Revista

de Letras e de Floema.

Caderno de Teoria e

História Literária (UESB).

MARÍLIA LIBRANDI ROCHA

\section{e 0 teatro}

impossível

de teatro

\author{
Versão inicial deste texto foi \\ apresentada no III Seminário \\ Internacional Guimarães Rosa, \\ PUC-Minas, em agosto de 2004 \\ A expressão "teatro impossivel de \\ teatro", do título, remete à frase \\ de João Adolfo Hansen 12000 , p. \\ 43) a respeito de Grande Sertão: \\ Veredas: "Nonada', lê-se, e a cena \\ se abre como um teatro impossivel \\ de teatro".
}




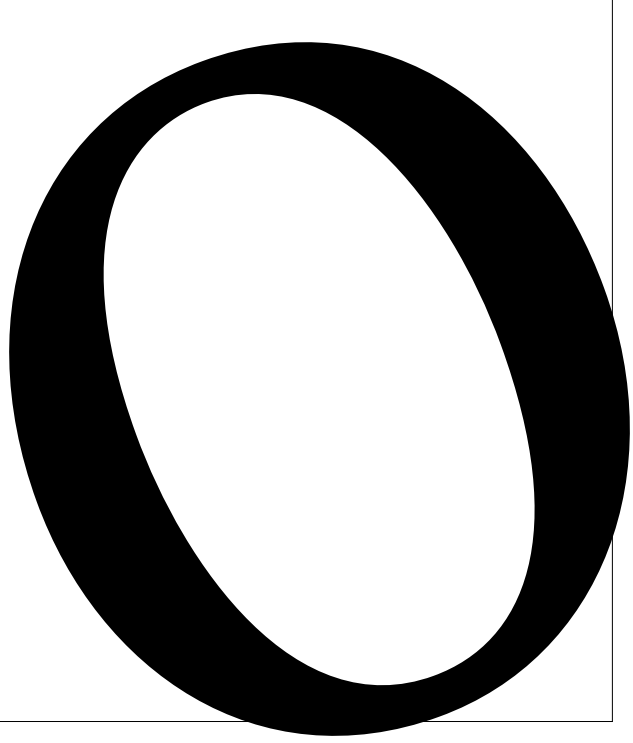

conto "Pirlimpsiquice" de João Guimarães Rosa, publicado em Primeiras Estórias (1962), é o tema de nossa leitura. $\mathrm{O}$ texto versa sobre uma apresentação teatral realizada por alunos de um colégio interno dirigido por padres. Nosso intuito é compreender o que foi esse evento discutindo a noção de representação como ação posta em cena para representar o irrepresentável: "[...] esse drama do agora, desconhecido, estúrdio, de todos o mais bonito, que nunca houve, ninguém escreveu, não se podendo representar outra vez, e nunca mais" (Rosa, 1962, p. 47). Em uma perspectiva comparada entre literatura e teatro, lançamos a proposta geral que orienta nossa leitura numa primeira abordagem relativa ao conceito de representação que aqui começamos a delinear.

O conto "Pirlimpsiquice" põe em cena - efetivamente encena pela narração - a questão da representação no teatro. Trata-se assim, se retomarmos a distinção platônica dos modos de composição verbal, de uma narração ou relato simples, diegesis, que versa sobre o grau máximo de representação, a mímesis, modo este de encenação direta da história através das falas dos personagens (como na tragédia e na comédia). Esse grau máximo de mímesis, quando o autor sai de si para falar como outros mimetizando a fala dos personagens, é o mais perigoso e o mais contagiante, e será condenado por Platão no Livro III da República, pois é o modo mimético de identificação e empatia que mais contagia o público e que deve ser controlado, regulado e, inclusive, expulso tendo em vista a educação do cidadão (cf. Havelock, 1996).

Nossa hipótese de leitura mais ampla é a de que o conto de Guimarães Rosa reencena a expulsão da mímesis ou sua regulação com vistas à educação, lembrando que ele narra um evento, a apresentação teatral que ocorre no interior de uma instituição educacional, e o perigo desse evento, que fará com que os padres falem em pôr fim a festas dessas no colégio. Relembremos então o enredo do conto, a sua história ou muthos, tal como narrada em primeira pessoa por aquele que, no passado, esteve no auge e no ápice da cena: o ponto. Veremos então a questão do ponto e sua função na representação entendida como imitação e a sua crítica segundo a proposta de Jacques Derrida lendo Antonin Artaud. Como se verá, não se quer comparar os dois autores, mas verificar que a obra de Guimarães Rosa insere-se numa série literária que encontra, no questionamento da representação como imitação, a precisão de uma poética que pensa a arte como modo de ação transcendente para escapar às dicotomias e fazer valer uma terceira possibilidade não realizável no mundo em que vivemos, mas cuja possibilidade apenas essa arte poderia apontar: “A arte não é imitação da vida, mas a vida é a imitação de um princípio transcendente com o qual a arte nos volta a pôr em comunicação", dizArtaud (apud Derrida, 1995,p. 153). Pensamos ler no texto de Guimarães Rosa uma proposta semelhante a essa no interior mesmo de sua diferença. Quanto à diferença das propostas, ela se encontra no modo como o texto de Rosa questiona a representação clássica, com humor, ao invés da tragicidade que há na arte e na vida de Antonin Artaud.

\section{ENREDO DO CONTO}

Assim inicia-se o conto*:

"Aquilo na noite do nosso teatrinho foi de Oh. O estilo espavorido. Ao que sei, que se saiba, ninguém soube direito o que houve. Ainda, hoje adiante, anos, a gente se lembra: mas, mais do repente que da desordem, e menos da desordem do que do rumor. Depois, os padres falaram em pôr fim a festas dessas, no Colégio” (p. 39). 
A primeira frase anuncia o evento que vai ser tema da narração como: “Aquilo [...] foi de Oh". Algo ocorreu no "teatrinho", mas não sabemos o que, incluindo o narrador, que reitera o verbo saber três vezes para enfatizar o não-saber, pois "ninguém soube direito o que houve". Não há uma designação para o evento ocorrido no teatro a não ser a exclamativa, onomatopaica “Oh”. Linguagem primeira ou linguagem da ausência de linguagem, a onomatopéia apenas pode indiciar o efeito do que houve, mas não conceituá-lo. Ao qualificar o estilo do que houve como "espavorido", o autor lança mão de um termo arcaizante datado do século XV para dizer do efeito de um estilo apavorado, efeito esse que poderíamos aproximar daquele descrito por Aristóteles na Poética, como a finalidade da apresentação teatral trágica: o pavor e a piedade através dos quais o espectador purga suas emoções catarticamente. Foi, então, provavelmente esse efeito "espavorido", manifesto no espanto do "Oh" de seu estilo, que teve como conseqüência o fim de festas como essa no colégio.

O narrador conta-nos então a história. Um grupo de doze alunos de um internato é chamado a representar um drama em cinco atos intitulado Os Filhos do Doutor Famoso. O fato é anunciado pelo padre Prefeito, "solene modo", e o professor de corografia e história-pátria dr. Perdigão é designado para ser o ensaiador. No decorrer do conto, aparecem em negrito as máximas que o dr. Perdigão vai transmitindo aos alunos, tais como: "Representar é aprender a viver além dos levianos sentimentos, na verdadeira dignidade"; "Lembrem-se: circunspecção e majestade"; "Longa é a arte e breve a vida - um preconício dos gregos"; “Sus! Brio! Obstinemo-nos. Decoro e firmeza, Ad astra per aspera! Sempre dúcteis ao meu ensinamento...".

Aos leitores, porém, não se expõe qual é a história do drama, apenas indiciada pelos nomes-funções das personagens que sugerem um enredo de gênero policial. Os personagens são o Doutor Famoso e seus quatro filhos cognominados: Filho Capitão, Filho Padre, Filho Poeta, Filho Criminoso, o qual, para não causar embaraço, é rebatizado pelos padres como “O Redimido”. Há ainda "o Amigo", “O Homem que sabia o segredo",o "Delegado", “um policial, outro policial e o "Criado", também pelo mesmo motivo rebatizado pelos padres como "o Flâmulo".

Entre os alunos escolhidos para a apresentação, Ataualpa deve representar o personagem principal, o Doutor Famoso; outros representam os filhos e é incluída a participação de um aluno especial, Zé Boné, que deveria fazer o papel de um policial. Este, porém, era "beócio" e "basbaque".

“Zé Boné, com efeito, regulava de papalvo. Sem fazer conta de companhia ou conversas, varava os recreios reproduzindo fitas de cinema: corria e pulava, à celerada, cá e lá, fingia galopes, tiros disparava, assaltava a mala-posta, intimando e pondo mãos ao alto, e beijava afinal - figurado a um tempo de mocinho, moça, bandidos e xerife. Dele, bem, se ria. O basbaque" (p. 40).

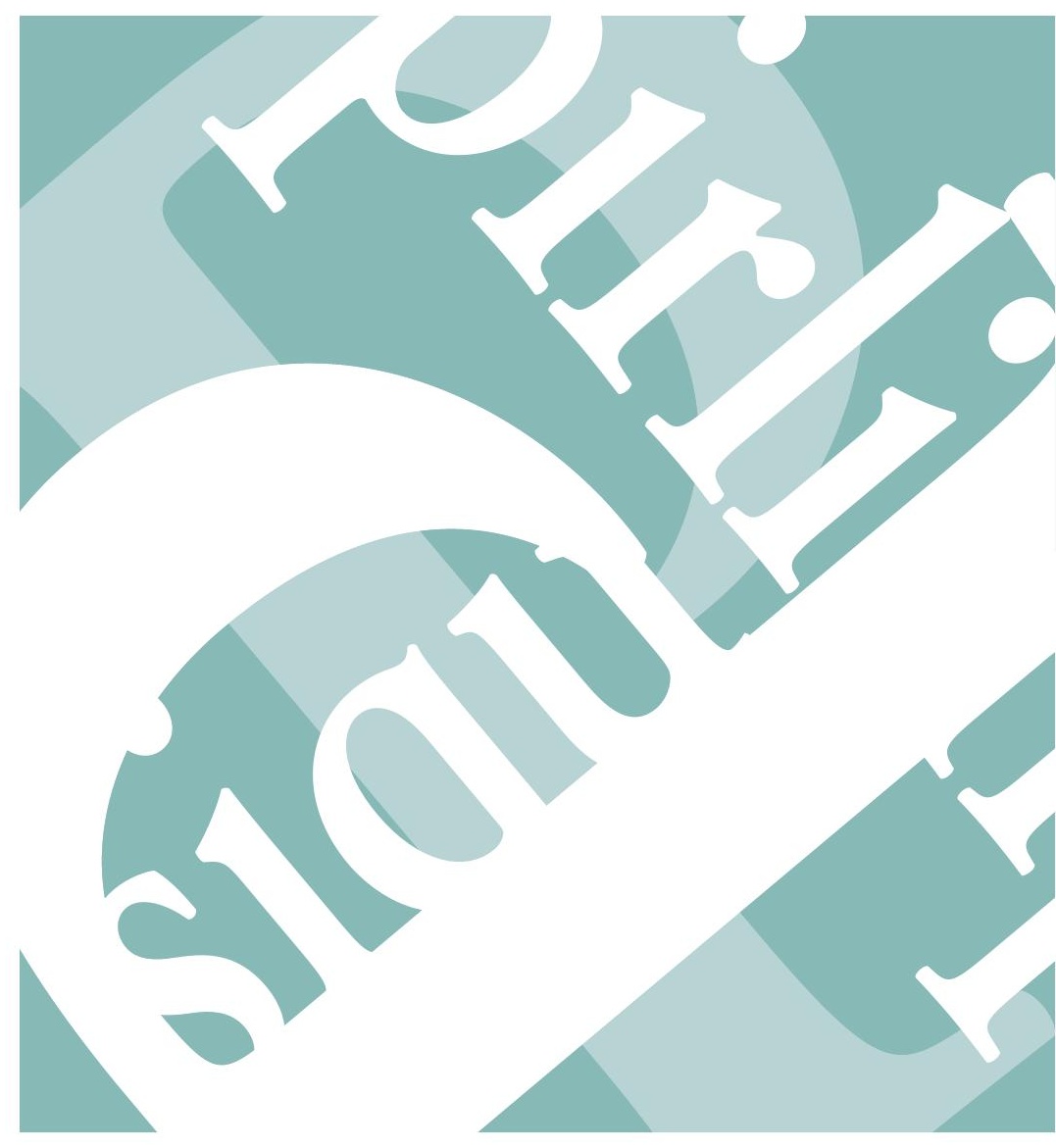


Nos recreios, ele representava todos os papéis ao mesmo tempo, descrevivendo as cenas que via nas telas do cinema. Zé Boné é assim mais um dos personagens de exceção, recorrentes na obra de Rosa, e que operará a reviravolta do conto, já indiciada no uso desse termo descreviven$d o$, aglutinando o descrever e o viver em um único vocábulo: “[...] pois, enquanto recreios houvesse, continuava ele descrevivendo-as, com aquela valentia e o ágil não-se-cansar, espantantes". Durante os ensaios, vendo que ele não atinava com palavra-e-meia do drama e que não haveria modo de fazê-lo representar com adequação, o professor o intima “a representar de mudo, apenas proibido de abrir a boca em palco".

Já o narrador, de quem não sabemos o nome, por ser "aluno aplicado, e com voz variada, certa, de recitador”, seria o "ponto", aquele que no teatro ou no espaço do buraco do palco, espécie de alçapão em que fica instalado e oculto do público, tem a função de soprar as falas para os atores em cena.

A participação na peça garante aos alunos um privilégio frente aos demais, ficando de fora os alunos "mal-comportados incorrigíveis", apelidados Tãozão e Mãona-Lata (como nomes de vilões de história em quadrinhos). Como há facções em luta no interior do colégio, fica conveniado entre os alunos-atores: "Ninguém conta nada aos outros, do drama!". Receando que os outros os forçassem a contar a história original, eles armam um estratagema inventando uma outra história para ludibriar os alunos-adversários: "E um cá, teve a idéia. Precisávamos de imaginar, depressa, alguma outra estória, mais inventada, que íamos falsamente contar, embaindo os demais no engano".

“Mas, a outra estória, por nós tramada, prosseguia, aumentava, nunca terminava, com singulares-em-extraordinários episódios, que um ou outro vinha e propunha [...]. Já, entre nós, era a 'nossa estória', que, às vezes, chegávamos a preferir à outra, a 'estória de verdade' do drama” (p. 41).
Ao mesmo tempo, um dos alunos, "de muita inventiva e lábia", começa a espalhar uma terceira história. Os outros adversários:

"Diziam já saber a verdadeira estória do drama, e que não passávamos de impostores. De certo, circulava outra versão, completa, e por sinal bem aprontada, mas de todo mentirosa. Quem a espalhara? O Gamboa, engraçado, de muita inventiva e lábia, que afirmava, pés juntos, estar dono da verdade" (p. 42).

Instaura-se assim a disputa pela ordem do discurso "dono da verdade" da história "original": "Repetíamos, então, sem cessar, a nossa estória, com forte cunho de sinceridade. Sempre ficavam os partidários de uma e de outra, não raro, bandeando campo, vez por vez, por dia." (p. 42). Três histórias, portanto, passam a circular: a história do drama, original; a história inventada pelos alunos-atores e a história inventada pelos alunos-adversários. Surge aqui a estrutura de encaixe de uma história dentro da outra, recorrente nos textos de Guimarães Rosa e que contribui para essa estrutura en abîme, na qual a história primeira, original, “de verdade”, que é já uma ficção, é suplantada por outras, também fictícias, que tomam o lugar da primeira, de modo que já não se tem mais um primeiro, mas simulacros sucessivos perturbando e desestabilizando os lugares estabelecidos.

No dia da apresentação, ocorre a reviravolta ou peripécia: o aluno Ataualpa, que fazia o papel principal do Dr. Famoso, na hora e vez da apresentação tem de viajar para ver o pai que está à morte no Rio de Janeiro. Decide-se então que o único que poderia substituí-lo seria o ponto, função que seria então assumida pelo Dr. Perdigão. De ponto, o menino agora se torna Dr. Famoso e deve abrir a cena:

"E a hora enorme. O teatro, imensamente, a platéia: - Ninguém mais cabe! - o povoréu de cabeças, estrondos de gente entrando e se sentando, rumor, rumor, oh as luzes. [...] Era a hora na hora. Parecia que nos 
empurravam para o de todo sem propósito. Me punham para a frente. Só ouvi as luzes, risos, avistei demais. O silêncio. Eu estava ali, parado, em pé, de fraque, a beira-mundo do público, defronte. Eque queriam de mim, que esperavam?" (p. 45).

O posto principal é assumido por aquele que iria ficar oculto. No entanto, ao subir no palco ele se dá conta de que não sabe os versos iniciais que falavam sobre a Virgem Maria e que seriam declamados pelo aluno que partiu. Branco, pausa, buraco, a representação não começa, os padres se inquietam: “Eu, não. Eu: teso e bambo, no embondo, mal em suor frio e quente, não tendo dá-me-dá, gago de êêê, no sem-jeito, só espanto. O minuto parou". Não sabendo então o que fazer, grita num ímpeto: "Viva a Virgem e viva a Pátria!". Ouvem-se aplausos, há nova confusão, o diretor pede para que abaixem o pano, mas a maquinaria enguiça e o pano não abaixa, o público começa a vaiar e a chamar: "Zé Boné! Zé Boné!".

"Foi a conta.

Zé Boné pulou para diante, Zé Boné pulou de lado. Mas não era de faroeste, nem em estouvamento de estrepolias. Zé Boné começou a representar!

A vaia parou, total.

Zé Boné representava-de rijo e bem, certo, a fio, atilado - para toda a admiração. Ele desempenhava um importante papel, o qual a gente não sabia qual. Mas, não se podia romper em riso. Em verdade. Ele recitava com muita existência” (p. 46).

Os outros então passam a atuar, contracenando. O que eles representamé a história que inventaram, mesclada com parte da história "original" e da história inventada pelos alunos-adversários.

“A princípio, um disparate - as desatinadas pataratas, nem que jogo de adivinhas. Dr. Perdigão se soprava alto, em bafo, suas réplicas e deixas, destemperadas. Delas, só a pouca parte se aproveitava. O mais eram ligeirias - e solertes seriedades. Palavras de outro ar. Eu mesmo não sabia o que ia dizer, dizendo, e dito - tudo tão bem - sem sair do tom" (pp. 46-7).

O que representam é o "drama do agora":

"[...] que tudo tinha e tomava o forte, belo sentido, esse drama do agora, desconhecido, estúrdio, de todos o mais bonito, que nunca houve, ninguém escreveu, não se podendo representar outra vez, e nunca mais. Eu via os do público assungados, gostando, só no silêncio completo. Eu via - que a gente era outros - cada um de nós, transformado. O Dr. Perdigão devia de estar soterrado, desmaiado em sua correta caixa-do-ponto" (p. 47).

\section{O PONTO. DERRIDA E A PALAVRA SOPRADA}

Em dois textos de meados dos anos 60, “A Palavra Soprada" (1965) e "O Teatro da Crueldade e o Fechamento da Representação" (1966), publicados em A Escritura $e$ $a$ Diferença, Jacques Derrida lê o apelo de Antonin Artaud. Como diz, não se trata de apresentá-lo como exemplo nem esperar dele uma lição ou tomá-lo por um caso clínico, mas compreender "o sentido de uma arte que não dá ocasião para obras”. Podemos caracterizar o evento em "Pirlimpsiquice" também como uma não-obra, pois que não permite a repetição. O evento acontecido no "teatrinho" é irrepetível: "[...] esse drama do agora, desconhecido, estúrdio, de todos o mais bonito, que nunca houve, ninguém escreveu, não se podendo representar outra vez, e nunca mais" (Rosa, 1962, p. 47).

Por "palavra soprada", Derrida entende a inserção do homem em um sistema cultural (político e social) que está sempre soprando o que deve ser dito e pensado, roubando e furtando-lhe o direito a uma palavra sem princípios nem fins e que fosse sempre primeira ou a cada vez sempre primeiras estórias. A “palavra soprada” é também 
aquela "inspirada" por outras vozes e que é alegorizada pela função do ponto no teatro: “[...] a estrutura do teatro clássico em que a invisibilidade do ponto assegura a diferença e a interrupção indispensáveis entre um texto já escrito por uma outra mão e um intérprete já despojado daquilo mesmo que recebe" (Derrida, 1995, p. 117). Por isso:

“Artaud quis a conflagração de uma cena em que o ponto fosse possível e o corpo às ordens de um texto estranho. Artaud quis que fosse destroçada a maquinaria do ponto. Fazer voar em estilhaços a estrutura do roubo. Para isso era necessário, com um único e mesmo gesto, destruir a inspiração poética e a economia da arte clássica, especialmente do teatro. Destruir ao mesmo tempo a metafísica, a religião, a estética, etc., que as sustentariam e abrir assim ao Perigo um mundo em que a estrutura do furto não oferecesse mais nenhum abrigo. Restaurar o Perigo despertando a Cena da Crueldade, tal era pelo menos a intenção declarada de Antonin Artaud" (Derrida, 1995, p. 117).

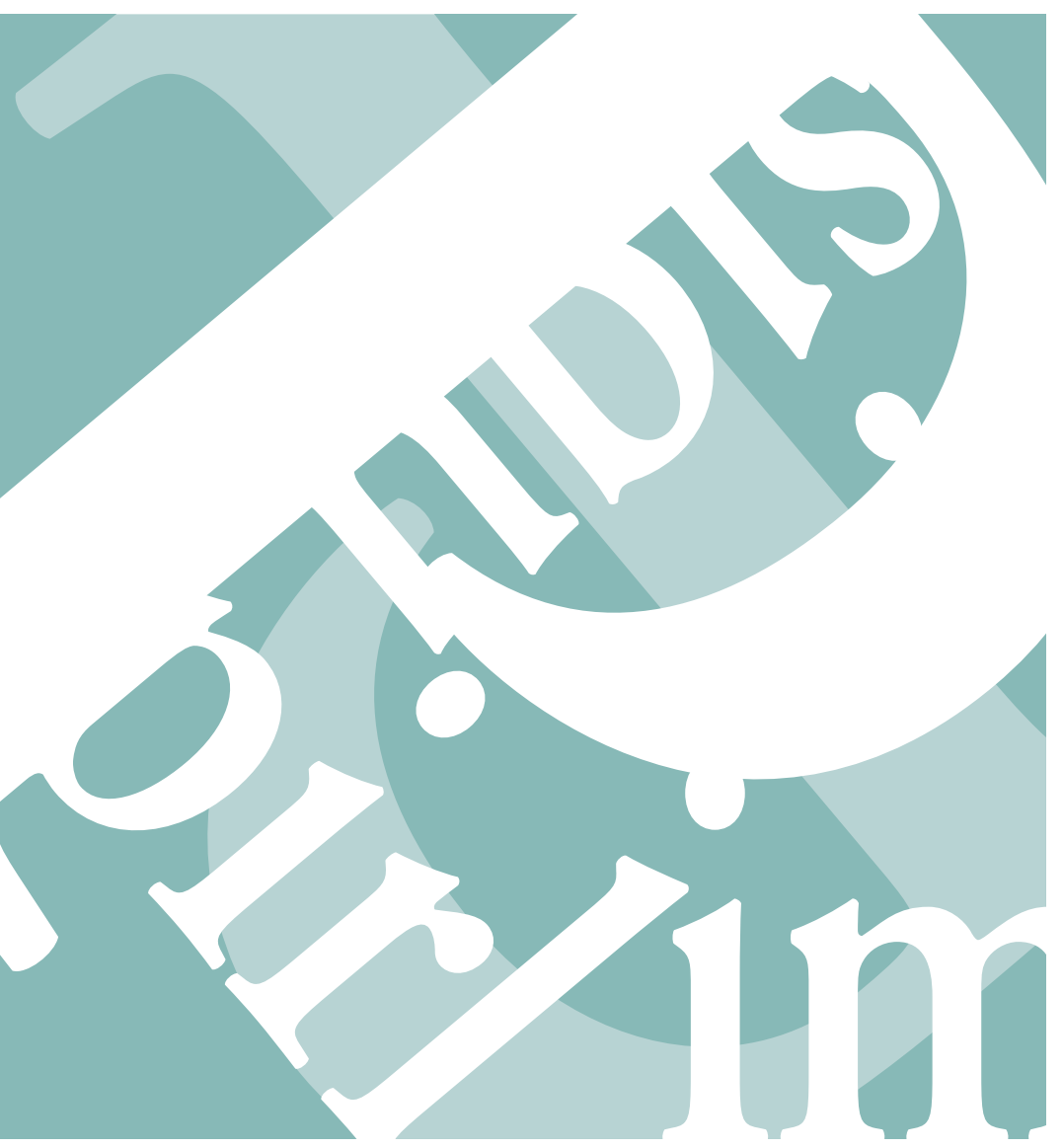

A palavra não mais soprada implica também a defesa do "impoder":

"[...] a irrupção positiva de uma palavra que vem não sei donde, acerca da qual sei, se for Antonin Artaud, que não sei donde vem nem quem a fala, essa fecundidade do outro sopro é o impoder: não a ausência mas a irresponsabilidade radical da palavra, a irresponsabilidade como poder e origem da palavra. Relaciono-me comigo no éter de uma palavra que meé sempre soprada e que me furta exatamente aquilo com que me põe em contato" (Derrida, 1995, p. 118).

Como ocorre em "Pirlimpsiquice" a estrutura da "palavra soprada" pelo ponto é substituída por: "Palavras de outro ar. Eu mesmo não sabia o que ia dizer, dizendo, e dito - tudo tão bem - sem sair do tom" (Rosa, 1962, p. 47).

No texto "O Teatro da Crueldade e o Fechamento da Representação”, Derrida mostra que o "teatro da crueldade" está por nascer, ainda não começou a existir, e anuncia o limite da representação ao produzir um espaço não-teológico. $\mathrm{O}$ palco é teológico enquanto for dominado pela palavra de um autor-criador que, ausente e distante, comanda a representação soprando as idéias que devem ser repetidas. É teológico pela presença de diretores e atores que representam personagens desse autor-criador: "Escravos interpretando, executando fielmente os desígnios providenciais do 'senhor'" (Derrida, 1995b, p. 154). Nessa estrutura geral jamais modificada “o irrepresentável do presente vivo é dissimulado ou dissolvido". Por isso: "Como Nietzsche - e as afinidades não seriam apenas estas - Artaud quer portanto acabar com o conceito imitativo de arte" (Derrida, 1995b, p. 153). A esse respeito encontramos observação de Dirce Cortes Riedel, a respeito de Guimarães Rosa, que mostraria a semelhança na diferença dessas propostas: “Guimarães Rosa é um nietzschiano que não mata Deus, mas questiona o humano e abala nossos fundamentos" (Riedel, 1980, p. 11). “E é o texto fonético, a palavra, o discurso transmitido - eventualmente pelo ponto cujo 
buracoé o centro oculto, mas indispensável da estrutura representativa - que assegura o movimento da representação" (Derrida, 1995, p. 155).

Na proposta de Artaud é o "triunfo da encenação pura" que se busca e que estaria na véspera da representação teatral, na origem da tragédia, nos Mistérios Órficos e nos Mistérios de Elêusis. O que houve nos vinte e cinco séculos, segundoele, foi uma perversão e não apenas esquecimento, por isso também a função de ressuscitar essa cena: “Quer isto dizer que Artaud teria recusado dar o nome de representação ao teatro da crueldade? Não, desde que nos entendamos bem acerca do sentido difícil e equívoco desta noção" (Derrida, 1995, p. 157).

Derrida detém-se então no significado das palavras alemãs que traduzimos por esse único termo “representação", definindo seus três usos: 1) A representação (teatral) como “ilustração sensível a um texto já escrito, pensado ou vivido fora dela e que não faria mais do que repetir, cuja trama não constituiria"; 2) a representação como repetição de um presente que estaria em outro lugar e seria anterior à representação; 3) A representação como superfície exposta de um espetáculo oferecido a curiosos. Artaud buscaria uma "representação originária" (Derrida, 1995, pp. 157-8).

“E a não-representação é portanto representação originária, se representação significa também desdobramento de um volume, de um meio em várias dimensões, experiência produtora de seu próprio espaço. Espaçamento, isto é, produção de um espaço que nenhuma palavra poderia resumir ou compreender [...]"'(Derrida, 1995, p. 157).

A palavra na cena não mais como ordem ou recitação mas como gestos:

“[...] desnuda-se a carne da palavra, a sua sonoridade, a sua entoação, a sua intensidade, o grito que a articulação da língua e da lógica ainda não calou totalmente, aquilo que em toda a palavra resta de gesto oprimido, esse movimento único e insubstituível que a generalidade do conceito e da repetição nunca deixaram de recusar" (Derrida, 1995, p. 161).

Por isso o valor da onomatopéia como véspera da origem das línguas:

"Sabe-se o valor que Artaud dava àquilo que se denomina - no caso muito impropriamente - onomatopéia. A glossopoiese, que não é nem uma linguagem imitativa nem uma criação de nomes, reconduz-nos à beira do momento em que a palavra ainda não nasceu, em que a articulação não mais é grito mas ainda não é discurso, em que a repetição é quase impossível, e com ela a língua em geral [...]. É a véspera da origem das línguas e desse diálogo entre a teologia e o humanismo cuja repetição infindável e metafísica do teatro ocidental sempre manteve" (Derrida, 1995, p. 161).

"Artaud quer o teatro hierático como experiência mística. Mas não seria o divino inventado pelo homem, pois foi a intervenção do homem que corrompeu o divino. 'A restauração da divina crueldade passa portanto pelo assassínio de Deus, isto é, em primeiro lugar do homem-Deus"' (Derrida, 1995, p. 166).

\section{FIM DA REPRESENTAC̦ÃO SEM FIM}

Ao final do conto "Pirlimpsiquice" a representação sem fim é interrompida pelo gesto do menino que salta do palco, pula para fora da cena, literalmente cai, de novo, na real. Volta então a disputa pelo discurso da verdade, o verdadeiro drama, ficando em suspenso o encantamento das palavras de outro ar ou a esquisitice de uma psiquê que alça vôo além das palavras sopradas. E a cena ao final volta ao ponto de que partiu:

"Mas-de repente-eu temi? Ameio, a medo, acordava, e daquele estro estrambótico. $\mathrm{O}$ que: aquilo nunca parava, não tinha começo nem fim? Não havia tempo decorrido. E como ajuizado terminar, então? Precisava. E fiz uma força, comigo, para me soltar do 
encantamento. Não podia, não me conseguia - para fora do corrido, contínuo, do incessar. Sempre batiam, um ror, novas palmas. Entendi. Cada um de nós se esquecera de seu mesmo, e estávamos transvivendo, sobrecrentes, disto: que era o verdadeiro viver? $\mathrm{E}$ era bom demais, bonito - o milmaravilhoso - a gente voava, num amor, nas palavras: no que se ouvia dos outros e no nosso próprio falar. E como terminar?

Então, querendo e não querendo, e não podendo, senti: que - só de um jeito. Só uma maneira de interromper, só a maneira de sair - do fio, do rio, da roda, do representar sem fim. Cheguei para a frente, falando sempre, para a beira da beirada. Ainda olhei, antes. Tremeluzi. Dei a cambalhota. De propósito, me despenquei. E caí.

$\mathrm{E}$, me parece, o mundo se acabou.

Ao menos, o daquela noite. Depois, no outro dia, eu são, e glorioso, no recreio, então o Gamboa veio, falou assim: - 'Eh, eh, hem? Viu como era que a minha estória também era a de verdade?' Pulou-se, ferramos fera briga" (p. 48).
Como vimos, o conto de Guimarães Rosa narra o que foi uma encenação teatral no interior de uma instituição educacional regida pelos princípios humanísticos incorporados pelos padres da Igreja que dirigem a escola. No interior desse internato, uma cena irrompe, incontrolável. É a "representação sem fim". O perigo dessa irrupção faz com que eventos como esse sejam abolidos da instituição. Nossa hipótese de leitura é, pois, a de que o conto de Guimarães Rosa reencena a expulsão da mímesis que por um momento reinou, trazendo à beiramundo do palco a possibilidade de uma outra cena não mais regida pela distinção vida-arte, mas pelo “impoder” de uma fala que vem não se sabe de onde e que teve de ser interrompida para que se retomasse a cotidianidade dos jogos de poder instaurados no discurso. Restaria agora avançar o estudo com outras perspectivas na abordagem da relação literatura e teatro ou da teatralidade na literatura de Guimarães Rosa e na compreensão da representação como encenação.

\section{BIBLIOGRAFIA}

DERRIDA, Jacques. "A Palavra Soprada", in A Escritura e a Diferença. Traduccão Maria Beatriz Marques Nizza da Silva.

2a ed. São Paulo, Perspectiva, 1995, pp. 107-47.

"0 Teatro da Crueldade e o Fechamento da Representação", in A Escritura e a Diferença. Tradução Maria

Beatriz Marques Nizza da Silva. 2ª ed. São Paulo, Perspectiva, 1995, pp. 149-77.

HANSEN, J. A. 00 - A Ficção da Literarura em Grande Sertão:Veredas. São Paulo, Hedra, 2000.

HAVELOCK, Eric. Prefácio a Platão. Tradução Enid Abreu Dobránzsky. Campinas, Papirus, 1996.

PLATÃO. República. Tradução Maria Helena da Rocha Pereira. 7@̣ ed. Lisboa, Fundação Calouste Gulbenkian, 1993.

RIEDEL, Dirce Cortes. Meias-verdades no Romance. Rio de Janeiro, Achiamé, 1980.

ROSA, João Guimarães. "Pirlimpsiquice”, in Primeiras Estórias. 4a ed. Rio de Janeiro, José Olympio, 1962, pp. 38-48. 